\title{
PENGARUH KESADARAN WAJIB PAJAK, SANKSI PAJAK DAN PELAYANAN PAJAK TERHADAP KEPATUHAN WAJIB PAJAK ORANG PRIBADI PADA KANTOR PELAYANAN PAJAK PRATAMA CILEUNGSI, KABUPATEN BOGOR
}

\author{
${ }^{1)}$ Muhlis, ${ }^{2)}$ Novi Trisna \\ ${ }^{1)}$ Dosen Program Studi Manajemen, STIE Dewantara \\ Jl. Raya Pemda Bojong Depok Baru III, Karadenan, Cibinong, Bogor, Jawa Barat 16913, Indonesia \\ Email: muhlis@dewantara.ac.id \\ ${ }^{2)}$ Alumni Program Studi Manajemen, STIE Dewantara \\ Jl. Raya Pemda Bojong Depok Baru III, Karadenan, Cibinong, Bogor, Jawa Barat 16913, Indonesia \\ Email: novitrisna56@gmail.com
}

\begin{abstract}
This research is aimed to investigate the effect of taxpayer awareness, tax sanctions, and tax services on individual taxpayer compliance at the Pratama Cileungsi tax service office, Bogor regency. The population of this study is an individual taxpayer. This research used Accidental Sampling technique, amounting to 100 samples. The results showed that tax sanctions had a significant effect on the level of compliance. The results of the $t$ test on the tax sanctions variable (X2) obtained t count of 5.505. The $t$ test result for the tax sanction variable was $5.505>1.985$ with a significance level of $0.000<0.5$. The results of the value of Fcount $>$ Ftable or 13.615> 2.36 collectively, the taxpayer awareness variable, tax sanctions and, tax services have a significant effect on individual taxpayer compliance. Linear regression test results obtained $Y=15.072+0.030 X 1+0.607 X 2+0.030 X 3+e$. The result of the coefficient of determination test shows that the $R$ Square value is 29.8 percent.
\end{abstract}

Keywords: Taxpayer Awareness, Tax Sanctions, Tax Services, Taxpayer Compliance, Individual Taxpayers.

\begin{abstract}
ABSTRAK
Penelitian ini bertujuan untuk mengetahui dan menganalisis pengaruh kesadaran wajib pajak, sanksi pajak dan pelayanan pajak terhadap kepatuhan wajib pajak orang pribadi pada kantor pelayanan pajak pratama cileungsi kabupaten Bogor. Populasi dari penelitian ini adalah wajib pajak orang pribadi. Penelitian ini menggunakan teknik Accidental Sampling yaitu berjumlah 100 sampel. Hasil penelitian menunjukkan bahwa sanksi pajak berpengaruh dan signifikan terhadap tingkat kepatuhan. Hasil uji t terhadap variabel sanksi pajak (X2) diperoleh $t_{\text {hitung }}$ sebesar 5,505 uji t untuk variabel sanksi pajak adalah 5,505 > 1,985 dengan tingkat signifikansi $0,000<0,5$. Hasil nilai $F_{\text {hitung }}>F_{\text {tabel }}$ atau 13,615 $>2,36$ secara bersama-sama variabel kesadaran wajib pajak, sanksi pajak dan pelayanan pajak memberi pengaruh yang signifikan terhadap kepatuhan wajib pajak orang pribadi. Hasil uji regresi linier diperoleh $\mathrm{Y}=15,072+0,030 \mathrm{X} 1+$ $0,607 \mathrm{X} 2+0,030 \mathrm{X} 3$ + e. Hasil uji koefisien determinasi menunjukkan bahwa nilai R Square sebesar 29,8 persen.
\end{abstract}

Kata kunci: Kesadaran Wajib Pajak, Sanksi Pajak, Pelayanan Pajak, Kepatuhan Wajib Pajak, Wajib Pajak Orang Pribadi.

\section{PENDAHULUAN \\ 1.1 Latar Belakang}

Sebagai negara yang berkembang sebenarnya Indonesia memiliki berbagai macam potensi yang dimiliki untuk menjadi negara yang lebih maju, dan sumber penerimaan negara Indonesia dibagi menjadi dua yaitu penerimaan dalam negeri dan penerimaan luar negeri, dan pajak merupakan salah satu sumber penerimaan negara. Akan tetapi pencapaian yang direncanakan oleh pemerintah, belum mencapai hasil yang maksimal. Hal ini dikarenakan masih banyaknya wajib pajak 
yang tidak melaporkan besarnya pajak sesuai yang diberikan pemerintah dan cenderung mengurangi biaya pajak yang sudah ditetapkan.

Pemungutan pajak memang bukan suatu yang mudah, selain peran serta aktif pegawai pajak, kesadaran masyarakat juga dituntut untuk membayar pajak. Pada umumnya wajib pajak cenderung untuk menghindarkan diri dari pembayaran pajak. Kecenderungan ini terjadi karena tingkat kesadaran wajib pajak yang masih rendah dan kurangnya pengetahuan dan pemahaman masyarakat terhadap peraturan perpajakan.

Berdasarkan laporan yang diperoleh dari Seksi Pengolahan Data dan Informasi (PDI) di KPP Cileungsi, dapat disimpulkan bahwa setiap tahun meningkatnya jumlah Wajib Pajak yang terdaftar di KPP Pratama Cileungsi.

Tabel 1. Perkembangan Jumlah Wajib Pajak Terdaftar

\begin{tabular}{|l|c|c|c|}
\hline \multicolumn{1}{|c|}{ Jenis WP } & $\mathbf{2 0 1 6}$ & $\mathbf{2 0 1 7}$ & $\mathbf{2 0 1 8}$ \\
\hline OP Non Karyawan & 8772 & 9971 & 11113 \\
\hline OP Karyawan & 109948 & 125274 & 139757 \\
\hline
\end{tabular}

Sumber: Seksi Pengolahan Data dan Informasi (PDI) KPP Pratama Cileungsi (2018)

Tabel 1. Menguraikan menguraikan setiap tahunnya terjadi kenaikan jumlah wajib pajak yang cukup besar dengan rincian sebagai berikut, Wajib pajak OP Non Karyawan sejak tahun 2016 sampai 2017 mengalami peningkatan jumlah wajib pajak sebesar 1199 dan pada tahun 2017 sampai 2018 mengalami peningkatan sebesar 1142 wajib pajak. Wajib pajak OP Karyawan sejak tahun 2016 sampai 2017 mengalami kenaikan yang cukup besar yaitu sebesar 15326 wajib pajak, dan pada tahun 2017 sampai 2018 terjadi peningkatan jumlah wajib pajak sebesar 14 483 wajib pajak.

Menurut Rochmat yang dikutip oleh Mardiasmo (2011:1) "pajak adalah iuran rakyat kepada kas negara berdasarkan undang-undang (yang dapat dipaksakan) dengan tidak mendapat jasa timbal balik yang langsung dapat ditunjukkan dan digunakan untuk membayar pengeluaran umum".

Wajib pajak orang pribadi menurut undang-undang nomor 28 tahun 2007 pasal 1 tentang ketentuan umum dan tata cara perpajakan menjelaskan bahwa wajib pajak adalah orang pribadi atau badan meliputi pembayaran pajak, pemotong pajak, dan pemungutan pajak, yang mempunyai hak dan kewajiban perpajakan sesuai dengan ketentuan peraturan perundang-undangan.

Menurut Zain dalam Wijoyanti (2010:40) kepatuhan wajib pajak adalah suatu iklim kepatuhan dan kesadaran pemenuhan kewajiban perpajakan yang tercermin dalam situasi dimana wajib pajak paham akan ketentuan peraturan perundang-undangan perpajakan.

Sanksi pajak merupakan salah satu faktor yang memengaruhi tinggi rendahnya kepatuhan wajib pajak. Wajib pajak akan memenuhi kewajibannya apabila memandang bahwa sanksi perpajakan akan lebih banyak merugikannya (Jatmiko:2006). Dengan adanya sanksi pajak maka kepatuhan wajib pajak akan meningkat.

\subsection{Rumusan Masalah}

Berdasarkan uraian di atas, rumusan masalah dalam penelitian ini adalah:

1. Bagaimana pengaruh kesadaran wajib pajak terhadap kepatuhan wajib pajak orang pribadi pada KPP Pratama Cileungsi?

2. Bagaimana pengaruh sanksi pajak terhadap kepatuhan wajib pajak orang pribadi pada KPP Pratama Cileungsi?

3. Bagaimana pengaruh pelayanan pajak terhadap kepatuhan wajib pajak orang pribadi pada KPP Pratama Cileungsi?

4. Bagaimana pengaruh kesadaran wajib pajak, sanksi pajak, dan pelayanan 
pajak terhadap kepatuhan wajib pajak orang pribadi pada KPP Pratama Cileungsi?

\subsection{Tujuan Penelitian}

Berdasarkan rumusan masalah, maka tujuan dari penelitian ini adalah:

1. Untuk mengetahui dan menganlisis pengaruh tingkat kesadaran wajib pajak terhadap kepatuhan wajib pajak orang pribadi pada KPP Pratama Cileungsi.

2. Untuk menegetahui dan menganlisis pengaruh sanksi pajak terhadap kepatuhan wajib pajak orang pribadi pada KPP Pratama Cileungsi.

3. Untuk mengetahui pengaruh pelayanan pajak terhadap kepatuhan wajib pajak orang pribadi pada KPP Pratama Cileungsi.

4. Untuk mengetahui dan menganlisis pengaruh kesadaran wajib pajak, sanksi pajak dan pelayanan pajak terhadap kepatuhan wajib pajak orang pribadi pada KPP Pratama Cileungsi.

\section{TINJAUAN PUSTAKA}

\subsection{Pajak}

Pajak adalah kontribusi wajib pajak kepada negara yang terutang oleh orang pribadi atau badan yang bersifat memaksa berdasarkan undang-undang dengan tidak mendapatkan imbalan secara langsung dan digunakan untuk keperluan negara bagi sebesar-besarnya kemakmuran rakyat (Mardiasmo, 2009:21).

\subsection{Wajib Pajak Orang Pribadi}

Menurut pasal 1 undang-undang nomor 28 tahun 2007 tentang ketentuan umum dan tata cara perpajakan menjelaskan bahwa wajib pajak adalah orang pribadi atau badan meliputi pembayaran pajak, pemotong pajak, dan pemungutan pajak yang mempunyai hak dan kewajiban perpajakan sesuai dengan ketentuan peraturan perundang-undangan perpajakan. (Resmi, 2009:21)

\subsection{Kesadaran Wajib Pajak}

Muliari dan Setiawan (2010), menyatakan bahwa kesadaran perpajakan adalah suatu kondisi dimana wajib pajak mengetahui, memahami, dan melaksanakan ketentuan perpajakan dengan benar dan sukarela. Indikator dari kesadaran perpajakan sebagai berikut:

1. Mengetahui adanya undang-undang dan ketentuan perpajakan

2. Mengetahui fungsi pajak untuk pembiayaan negara

3. Memahami bahwa kewajiban perpajakan harus dilaksanakan sesuai dengan ketentuan yang berlaku

4. Memahami fungsi pajak untuk pembiayaan negara

5. Menghitung, membayar, melaporkan pajak dengan sukarela

6. Menghitung, membayar, melaporkan pajak dengan benar

Kesadaran wajib pajak akan pentingnya membayar pajak demi bangsa akan membantu meningkatkan kepatuhan wajib pajak untuk membayar pajak secara benar, lengkap dan tepat waktu.

\subsection{Sanksi Pajak}

Menurut Mardiasmo (2006:39), sanksi perpajakan merupakan jaminan bahwa ketentuan peraturan perundang-undangan perpajakan akan dituruti/ditaati/dipatuhi, dengan kata lain sanksi perpajakan merupakan alat pencegah agar wajib pajak tidak melanggar norma perpajakan.

Penerapan sanksi diterapkan sebagai akibat tidak terpenuhinnya kewajiban perpajakan oleh wajib pajak sebagaimana diamanatkan oleh undang-undang perpajakan. Pengenaan sanksi pajak kepada wajib pajak dapat menyebabkan terpenuhinya kewajiban perpajakan oleh wajib pajak sehingga dapat meningkatkan kepatuhan wajib pajak itu sendiri. Wajib 
pajak akan patuh karena mereka berpikir adanya sanksi berat akibat tindakan illegal dalam usahanya menyelundupkan pajak. (Devano dan Rahayu, 2006:112)

\subsection{Pelayanan Pajak}

Pelayanan pajak dapat didefinisikan sebagai cara petugas pelayanan pajak dalam memberikan pelayanan dengan tanggap, kemampuan, kesopanan, dan sikap dapat dipercaya yang dimiliki oleh petugas pajak. (Zulaikha, 2013)

Menurut Kotler dan Keller (2010) pelayanan yang baik harusmengandung lima instrument serqual yang meliputi:

1. Tangible adalah wujud dari pelayanan yang diberikan petugas pajak kepada wajib pajak.

2. Reliability adalah konsistensi mutu dan kualitas pelayanan yang diberikan oleh petugas pajak kepada wajib pajak.

3. Assurance adalah jaminan yang diberikan kantor pajak kepada wajib pajak untuk mendapatkan pelayanan yang maksimal.

4. Responsibility adalah ketepatan dan keakuratan dalam pelayanan pajak yang diberikan petugas pajak kepada wajib pajak.

5. Emphaty adalah sikap peduli yang diperlihatkan petugas pajak kepada wajib pajak.

\subsection{Kepatuhan Wajib Pajak Orang Pribadi}

Kepatuhan perpajakan yang dikemukakan oleh (Moh Zain:2004) sebagai suatu iklim kepatuhan dan kesadaran pemenuhan kewajiban perpajakan tercermin dalam situasi (Devano dan Rahayu, 2006:110) sebagai berikut:

1. Wajib pajak paham atau berusaha untuk memahami semua ketentuan peraturan perundang-undangan perpajakan.

2. Mengisi formulir pajak dengan lengkap dan jelas.

3. Menghitung jumlah pajak yang terutang dengan benar.

\subsection{Kerangka Pemikiran}

Secara skematis dapat digambarkan kerangka pemikiran dalam penelitian ini seperti pada Gambar 1 berikut:

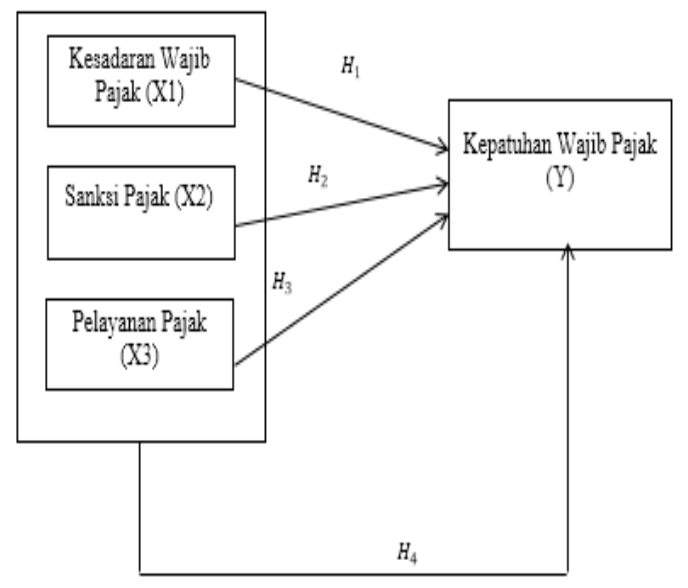

\section{Gambar 1. Kerangka Pemikiran}

\section{$2.8 \quad$ Hipotesis}

Hipotesis berperan sebagai pedoman pelaksanaan penelitian dan membantu membuat rancangan kesimpulan, adapun hipotesis yang diajukan dalam penelitian ini adalah:

$\mathrm{H}_{0}$ : Tidak terdapat pengaruh antara kesadaran wajib pajak, sanksi pajak dan pelayanan pajak terhadap kepatuhan wajib pajak orang pribadi pada KPP Pratama Cileungsi.

$\mathrm{H}_{1}$ : Terdapat pengaruh antara kesadaran wajib pajak terhadap kepatuhan wajib pajak orang pribadi pada KPP Pratama Cileungsi.

$\mathrm{H}_{2}$ : Terdapat pengaruh antara sanksi pajak terhadap kepatuhan wajib pajak orang pribadi pada KPP Pratama Cileungsi.

$\mathrm{H}_{3}$ : Terdapat pengaruh antara pelayanan pajak terhadap kepatuhan wajib pajak orang pribadi pada KPP Pratama Cileungsi.

$\mathrm{H}_{4}$ : Terdapat pengaruh secara bersamasama kesadaran wajib pajak, sanksi pajak dan pelayanan pajak terhadap kepatuhan wajib pajak orang pribadi pada KPP Pratama Cileungsi. 


\section{METODE PENELITIAN}

\subsection{Jenis Penelitian}

Jenis penelitian ini bersifat kuantitatif kausalitas yang merupakan tipe penelitian dengan karakteristik masalah hubungan sebab akibat antara dua variabel atau lebih.

Penelitian kausalitas menurut Sugiyono (2012:59) adalah hubungan yang bersifat sebab akibat. Penelitian kausalitas ini juga termasuk penelitian yang mengidentifikasikan fakta yang terjadi sebagai variabel yang dipengaruhi dan melakukan penyelidikan terhadap variabelvariabel yang mempengaruhi.

\subsection{Variabel Penelitian}

Variabel penelitian ini peneliti memberikan definisi secara jelas tentang variabel-variabel yang digunakan dalam penelitian ini. Variabel bebas (independen) kesadaran wajib pajak (X1), sanksi pajak (X2), pelayanan pajak (X3) dan variabel terikat (dependen) kepatuhan wajib pajak (Y).

\subsection{Lokasi dan Waktu}

Penelitian ini dilakukan di Kantor Pelayanan Pajak Pratama Cileungsi bulan Juni 2019. Waktu penelitian ini dilaksanakan selama enam bulan terhitung mulai dari bulan September 2019 hingga Februari 2020.

\subsection{Objek Penelitian}

Objek Penelitian ini adalah Faktorfaktor yang mempengaruhi Kesadaran Wajib Pajak, Sanksi Pajak dan Pelayanan Pajak terhadap Kepatuhan Wajib Pajak Orang Pribadi pada KPP Pratama Cileungsi. Adapun yang menjadi objek dalam penelitian ini adalah Wajib Pajak di Kantor Pelayanan Pajak Pratama Cileungsi.

\subsection{Populasi dan Sampel}

Populasi dalam penelitian ini adalah Wajib Pajak Orang Pribadi yang terdaftar di Kantor Pelayanan Pajak Pratama Cileungsi.
Sampel dalam penelitian ini adalah Wajib Pajak yang melaporkan Surat Pemberitahuan Tahunan sampai bulan Maret 2019.

Teknik penentuan sampel menggunakan Accidental sampling atau Sampling insidental.

\subsection{Tektik Analisis Data}

\subsubsection{Uji Kualitas Data}
a. Uji Validitas
b. Uji Reliabilitas

\subsubsection{Uji Asumsi Klasik}

a. Uji Normalitas

b. Uji Multikolinearitas

\subsubsection{Uji Hipotesis}
a. Analisis Regresi Linier Berganda
b. Uji F (Silmutan)
c. Uji t (Parsial)
d. Uji Koefisien Determinasi $\left(R^{2}\right)$

\section{HASIL DAN PEMBAHASAN}

\subsection{Uji Kualitas Data}

\subsubsection{Uji Validitas}

Uji validitas dilakukan untuk mengukur sah atau tidaknya indikator atau kuesioner dari masing-masing variabel. Pengujian dilakukan dengan membandingkan $r$ hitung dan $r$ tabel. Nilai $r$ hitung merupakan hasil korelasi jawaban responden dan pada masing-masing pernyataan disetiap variabel yang di analisis dengan program spss dan outputnya bernama corrected item correlation.

Tabel 2. Hasil Uji Validitas Variabel Kesadaran Wajib Pajak

\begin{tabular}{|c|c|c|c|}
\hline $\begin{array}{c}\text { Item } \\
\text { Pernyataan }\end{array}$ & $\begin{array}{c}\mathbf{R} \\
\text { tabel }\end{array}$ & $\begin{array}{c}\mathbf{R} \\
\text { hitung }\end{array}$ & Keterangan \\
\hline 1 & 0,1966 & 0,291 & Valid \\
\hline 2 & 0,1966 & 0,455 & Valid \\
\hline 3 & 0,1966 & 0,521 & Valid \\
\hline 4 & 0,1966 & 0,417 & Valid \\
\hline 5 & 0,1966 & 0,372 & Valid \\
\hline 6 & 0,1966 & 0,549 & Valid \\
\hline
\end{tabular}

Sumber : Data Primer yang diolah, 2019 
Berdasarkan data hasil pengujian validitas diatas, maka instrumen-instrumen yang digunakan untuk mengukur variabel dinyatakan valid karena $\mathrm{r}$ hitung untuk semua indikator variabel Kesadaran Wajib Pajak lebih besar dari nilai $r$ tabel.

Tabel 3. Hasil Uji Validitas Variabel Sanksi Pajak

\begin{tabular}{|c|c|c|c|}
\hline $\begin{array}{c}\text { Item } \\
\text { Pernyataan }\end{array}$ & $\begin{array}{c}\mathbf{R} \\
\text { tabel }\end{array}$ & $\begin{array}{c}\mathbf{R} \\
\text { hitung }\end{array}$ & Keterangan \\
\hline 7 & 0,1966 & 0,560 & Valid \\
\hline 8 & 0,1966 & 0,584 & Valid \\
\hline 9 & 0,1966 & 0,448 & Valid \\
\hline 10 & 0,1966 & 0,531 & Valid \\
\hline
\end{tabular}

Sumber : Data Primer yang diolah, 2019

Tabel 4. Hasil Uji Validitas Variabel Pelayanan Pajak

\begin{tabular}{|c|c|c|c|}
\hline $\begin{array}{c}\text { Item } \\
\text { Pernyataan }\end{array}$ & $\begin{array}{c}\mathbf{R} \\
\text { tabel }\end{array}$ & $\begin{array}{c}\mathbf{R} \\
\text { hitung }\end{array}$ & Keterangan \\
\hline 11 & 0,1966 & 0,505 & Valid \\
\hline 12 & 0,1966 & 0,416 & Valid \\
\hline 13 & 0,1966 & 0,320 & Valid \\
\hline 14 & 0,1966 & 0,372 & Valid \\
\hline
\end{tabular}

Sumber : Data Primer yang diolah, 2019

Tabel 5. Hasil Uji Validitas Variabel Kepatuhan Wajib Pajak

\begin{tabular}{|c|c|c|c|}
\hline $\begin{array}{c}\text { Item } \\
\text { Pernyataan }\end{array}$ & R tabel & $\begin{array}{c}\mathbf{R} \\
\text { hitung }\end{array}$ & Keterangan \\
\hline 15 & 0,1966 & 0,449 & Valid \\
\hline 16 & 0,1966 & 0,370 & Valid \\
\hline 17 & 0,1966 & $-0,012$ & Tidak Valid \\
\hline 18 & 0,1966 & 0,260 & Valid \\
\hline 19 & 0,1966 & 0,204 & Valid \\
\hline 20 & 0,1966 & 0,373 & Valid \\
\hline 21 & 0,1966 & 0,426 & Valid \\
\hline 22 & 0,1966 & 0,347 & Valid \\
\hline
\end{tabular}

Sumber : Data Primer yang diolah, 2019

Berdasarkan data hasil pengujian validitas diatas, maka instrumen-instrumen yang digunakan untuk mengukur variabel dinyatakan valid. Berdasarkan perbandingan antara hasil $r$ hitung dengan $r$ tabel pada Tabel 1.4. terlihat bahwa tidak semua pernyataan valid ada satu pernyataan, yaitu nomor 17 yang memiliki nilai kurang dari 0,1966. Pernyataan yang tidak valid tersebut tidak dapat digunakan dalam penelitian selanjutnya, jadi keseluruhan pernyataan yang dapat digunakan setelah uji validitas butir instrumen sebanyak 21 butir pernyataan.

\subsubsection{Uji Reliabilitas}

Uji reliabilitas digunakan untuk mengetahui apakah indikator atau kuesioner yang digunakan dapat dipercaya atau handal sebagai alat ukur variabel. Reliabilitas suatu indikator atau kuesioner dapat dilihat dari nilai Cronbach's alpha (a), yaitu apabila nilai Cronbach's alpha (a) lebih besar dari 0,4 maka indikator atau kuesioner adalah reliabel, sedangkan apabila nilai Cronbach's alpha (a) lebih kecil 0,4 maka indikator atau kuesioner tidak reliabel.

Tabel 6. Hasil Uji Reliabilitas Variabel Kesadaran Wajib Pajak

Reliability Statistics

\begin{tabular}{|r|r|}
\hline Cronbach's Alpha & \multicolumn{2}{|l|}{ N of Items } \\
\hline, 623 & \\
\hline
\end{tabular}

Sumber : Data Primer yang diolah, 2019

Dari hasil pengolahan di atas, maka instrumen-instrumen yang digunakan untuk mengukur variabel Kesadaran Wajib Pajak dalam penelitian ini dinyatakan layak atau cukup reliabel karena nilai Cronbach Alpha sebesar 0,623>0,40. Nilai Cronbach Alpha sebesar lebih dari 0,40 .

Tabel 7. Hasil Uji Reliabilitas Variabel Sanksi Pajak

Reliability Statistics

\begin{tabular}{|r|r|}
\hline Cronbach's Alpha & N of Items \\
\hline, 562 & \\
\hline
\end{tabular}

Sumber : Data Primer yang diolah, 2019 
Dari hasil pengolahan di atas, maka instrumen-instrumen yang digunakan untuk mengukur variabel Sanksi Pajak dalam penelitian ini dinyatakan layak atau cukup reliabel karena nilai Cronbach Alpha sebesar 0,562>0,40. Nilai Cronbach Alpha sebesar lebih besar dari 0,40 .

Tabel 8. Hasil Uji Reliabilitas Variabel Pelayanan Pajak

\begin{tabular}{|r|c|}
\hline \multicolumn{2}{|c|}{ Reliability Statistics } \\
\hline Cronbach's Alpha & N of Items \\
\hline, 793 & \\
\hline
\end{tabular}

Sumber : Data Primer yang diolah, 2019

Dari hasil pengolahan data di atas, maka instrumen-instrumen yang digunakan untuk mengukur variabel Pelayanan Pajak dalam penelitian ini dinyatakan layak atau reliabel karena nilai Cronbach Alpha sebesar 0,793 > 0,40. Nilai Cronbach Alpha sebesar lebih besar dari 0,40 .

Tabel 9. Hasil Uji Reliabilitas Kepatuhan Wajib Pajak

\begin{tabular}{|c|c|c|}
\hline Variabel & $\begin{array}{c}\text { Alpha } \\
\text { Cronbach }\end{array}$ & Keterangan \\
\hline $\begin{array}{c}\text { Kesadaran } \\
\text { Wajib Pajak }\end{array}$ & 0,623 & $\begin{array}{c}\text { Cukup Reliabel } \\
\text { (X1) }\end{array}$ \\
\hline Sanksi Pajak & 0,562 & $\begin{array}{c}\text { Cukup Reliabel } \\
\text { (X2) }\end{array}$ \\
\hline $\begin{array}{c}\text { Pelayanan } \\
\text { Pajak }\end{array}$ & 0,793 & Reliabel (X3) \\
\hline $\begin{array}{c}\text { Kepatuhan } \\
\text { Wajib Pajak }\end{array}$ & 0,401 & Cukup Reliabel (Y) \\
\hline
\end{tabular}

Sumber : Data Primer yang diolah, 2019

Dari hasil pengolahan di atas, maka instrumen-instrumen yang digunakan untuk mengukur variabel kepatuhan perpajakan dalam penelitian ini dinyatakan layak atau cukup reliabel karena nilai Cronbach Alpha sebesar 0,401 >0,40. Nilai Cronbach Alpha sebesar lebih besar dari 0,40 .

\subsection{Uji Asumsi Klasik}

\subsubsection{Uji Normalitas}

Uji Normalitas dilakukan untuk mengetahui apakah data yang digunakan pada penelitian ini berdistribusi norrmal atau tidak.

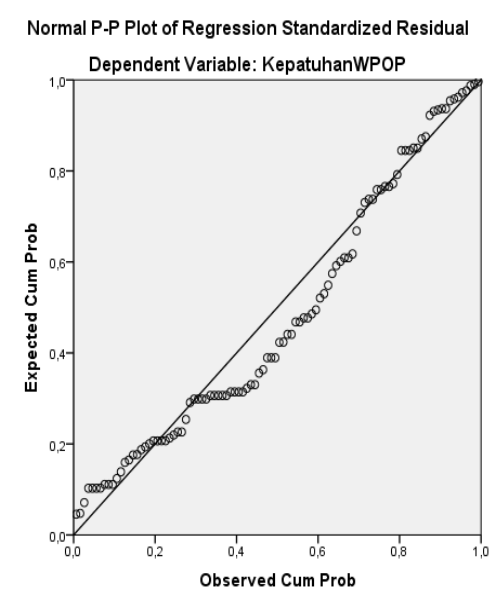

\section{Gambar 2. Hasil Uji P-Plot Normalitas}

Berdasarkan tampilan output chart di atas kita dapat melihat grafik histogram maupun grafik plot. Dimana grafik histogram memberikan pola distribusi yang melenceng ke kanan yang artinya adalah data berdistribusi normal. Selanjutnya, pada gambar P-Plot terlihat titik-titik mengikuti dan mendekati garis diagonalnya sehingga dapat disimpulkan bahwa model regresi memenuhi asumsi normalitas.

\subsubsection{Uji Multikolinearitas}

Uji Multikolinieritas digunakan untuk menguji apakah model regresi ditemukan adanya korelasi antar variabel independen. Model regresi yang baik seharusnya tidak terjadi korelasi diantara variabel independen. 
Tabel 10. Hasil Uji Multikolinearitas

\begin{tabular}{|c|r|r|}
\multicolumn{4}{|c|}{ Coefficients $^{\mathbf{a}}$} \\
\cline { 2 - 3 } Model & \multicolumn{2}{|c|}{ Collinearity Statistics } \\
\cline { 2 - 3 } 1 & \multicolumn{1}{|c|}{ Tolerance } & \multicolumn{1}{c|}{ VIF } \\
\hline $\begin{array}{l}\text { Kesadaran } \\
\text { WP }\end{array}$ &, 835 & 1,198 \\
$\begin{array}{l}\text { Sanksi } \\
\text { Pajak } \\
\begin{array}{l}\text { Pelayanan } \\
\text { Pajak }\end{array}\end{array}$ &, 805 & 1,242 \\
&, 909 & 1,100 \\
\hline
\end{tabular}

a. Dependent Variable: KepatuhanWPOP

Sumber : Data Primer yang diolah, 2019

Dari data di atas terlihat semua variabel memiliki nilai tolerance lebih besar 0.1 dan VIF lebih kecil 5. Artinya tidak terjadi multikolinieritas antar variabel.

\subsection{Uji Analisis Data}

\subsubsection{Uji Analisis Regresi Linier Berganda}

Analisis Regresi berganda digunakan oleh peneliti, bila peneliti bermaksud meramalkan bagaimana keadaan variabel dependen, bila dua atau lebih variabel independen sebagai faktor prediktor dimanipulasi (dinaik turunkan nilainya).

Tabel 11. Hasil Uji Analisis Regresi Linier Berganda

\begin{tabular}{|c|c|c|c|c|c|c|}
\hline \multicolumn{7}{|c|}{ Coefficients $^{\mathrm{a}}$} \\
\hline & \multirow[t]{2}{*}{ Model } & \multicolumn{2}{|c|}{$\begin{array}{l}\text { Unstandardized } \\
\text { Coefficients }\end{array}$} & \multirow{2}{*}{\begin{tabular}{|c|}
$\begin{array}{c}\text { Standardized } \\
\text { Coefficients }\end{array}$ \\
Beta \\
\end{tabular}} & \multirow{2}{*}{$\mathrm{T}$} & \multirow{2}{*}{ Sig. } \\
\hline & & B & Std. Error & & & \\
\hline \multirow[t]{4}{*}{1} & (Constant) & 15,072 & 2,136 & & 7,057 &, 000 \\
\hline & $\begin{array}{l}\text { Kesadaran } \\
\text { WP }\end{array}$ & 030 &, 078 &, 036 &, 384 &, 702 \\
\hline & $\begin{array}{l}\text { Sanksi } \\
\text { Pajak }\end{array}$ &, 607 &, 110 &, 524 & 5,505 &, 000 \\
\hline & $\begin{array}{l}\text { Pelayanan } \\
\text { Pajak }\end{array}$ &, 030 &, 120 &, 022 &, 250 &, 803 \\
\hline
\end{tabular}

Sumber : Data Primer yang diolah, 2019

Berdasarkan Uji Regresi seperti yang terlihat pada tabel (uji kolonieritas) diperoleh persamaan sebagai berikut:

$\mathrm{Y}=\mathbf{1 5 , 0 7 2}+\mathbf{0 , 0 3 0} \mathrm{X1}+\mathbf{0 , 6 0 7} \mathrm{X} 2+\mathbf{0 , 0 3 0}$ $\mathrm{X} 3+\mathrm{e}$

1. Nilai koefisien Kesadaran Wajib Pajak 0,030, maka setiap peningkatan 1 satuan sama dari Kesadaran Wajib Pajak maka akan meningkatkan Kepatuhan Wajib Pajak sebesar 0,030 satuan.

2. Nilai koefisien Sanksi Pajak 0,607, maka setiap peningkatan 1 satuan sama dari Sanksi Pajak maka akan meningkatkan Kepatuhan Wajib Pajak sebesar 0,607 satuan.

3. Nilai koefisien Pelayanan Pajak 0,030, maka setiap peningkatan 1 satuan sama dari Pelayanan Pajak maka akan meningkatkan Kepatuhan Wajib Pajak sebesar 0,030 satuan.

4. Nilai konstanta sebesar 15,072 menunjukkan bahwa dalam penelitian ini tanpa adanya faktor-faktor diatas responden sudah memiliki tingkat kepatuhan pajak sebesar 15,072 satuan.

\subsubsection{Uji F (Silmutan)}

Uji Simultan (Uji F) adalah pengujian untuk melihat pengaruh semua variabel independen terhadap variabel dependen, dengan cara membandingkan antara $F_{\text {hitung }}$ dengan $\mathrm{F}_{\text {tabel }}$ dimana nilai $\mathrm{F}_{\text {hitung }}$.

Tabel 12. Hasil Uji F (Silmutan)

\begin{tabular}{|c|r|r|r|c|c|}
\hline \multicolumn{7}{|c|}{ ANOVA $^{\mathrm{a}}$} \\
\hline Model & $\begin{array}{c}\text { Sum of } \\
\text { Squares }\end{array}$ & Df & $\begin{array}{c}\text { Mean } \\
\text { Square }\end{array}$ & F & Sig. \\
\hline Regression & 74,964 & 3 & 24,988 & 13,615 &, $000^{\circ}$ \\
1 Residual & 176,196 & 96 & 1,835 & & \\
Total & 251,16 & 99 & & & \\
\hline
\end{tabular}

a. Dependent Variable: KepatuhanWPOP

b. Predictors: (Constant), Pelayanan Pajak, Kesadaran WP, Sanksi Pajak

Sumber : Data Primer yang diolah, 2019

Berdasarkan Tabel 3 di atas diperoleh $\mathrm{F}_{\text {hitung }}=13,615$ dan derajat signifikansi $0,000<0,5 \%$ dan $\mathrm{N}-\mathrm{K}$ atau $100-4=96$ didapat $\mathrm{F}_{\text {tabel }}=2,706$. Ternyata bahwa nilai $\mathrm{F}_{\text {hitung }}>\mathrm{F}_{\text {tabel }}$ atau 13,615 $>2,706$ secara bersama-sama variabel kesadaran wajib pajak, sanksi pajak dan pelayanan pajak memberi pengaruh yang signifikan terhadap kepatuhan wajib pajak orang pribadi. 


\subsubsection{Uji t (Parsial)}

Uji hipotesis secara parsial dilakukan untuk mengetahui apakah ada pengaruh signifikan antara masing-masing variabel.

Tabel 13. Hasil Uji t (Parsial)

\begin{tabular}{|c|c|c|c|c|c|c|}
\hline \multicolumn{7}{|c|}{ Coefficients $^{\mathrm{a}}$} \\
\hline & \multirow[b]{2}{*}{ Model } & \multicolumn{2}{|c|}{$\begin{array}{l}\text { Unstandardized } \\
\text { Coefficients }\end{array}$} & \multirow{2}{*}{$\begin{array}{c}\begin{array}{c}\text { Standardized } \\
\text { Coefficients }\end{array} \\
\text { Beta }\end{array}$} & \multirow[b]{2}{*}{$\mathrm{t}$} & \multirow[b]{2}{*}{ Sig. } \\
\hline & & B & Std. Error & & & \\
\hline & (Constant) & 15,072 & 2,136 & & 7,057 &, 000 \\
\hline & $\begin{array}{l}\text { Kesadaran } \\
\text { WP }\end{array}$ &, 030 & 078 &, 036 &, 384 &, 702 \\
\hline & Sanksi Pajak &, 607 & , 110 &, 524 & 5,505 &, 000 \\
\hline & $\begin{array}{l}\text { Pelayanan } \mathrm{Pa} \\
\text { jak: }\end{array}$ & 030 &, 120 &, 022 & 250 & 803 \\
\hline
\end{tabular}

Sumber : Data Primer yang diolah, 2019

1. Hasil uji t terhadap variabel kesadaran wajib pajak (X1) diperoleh $t_{\text {hitung }}$ sebesar 0,384 dengan derajat signifikansi 0,702 . Uji t untuk variabel kesadaran adalah $0,384<1,984$ dengan tingkat signifikansi $0,702>$ $0,5 \%$. Ini menunjukkan variabel kesadaran tidak mempengaruhi tingkat kepatuhan wajib pajak orang pribadi.

2. Uji $\mathrm{t}$ variabel sanski pajak (X2) diperoleh $t_{\text {hitung }}$ sebesar 5,505 dengan derajat signifikansi 0,000 . Uji t untuk variabel sanksi pajak adalah 5,505 > 1,984 dengan tingkat signifikansi $0,000<0,5 \%$. Ini menunjukkan variabel sanksi pajak mempengaruhi tingkat kepatuhan wajib pajak orang pribadi. Hasil uji t terhadap variabel pelayanan pajak (X3) diperoleh $t_{\text {hitung }}$ sebesar 0,250 dengan derajat signifikansi 0,803 .

3. Uji t untuk variabel pelayanan pajak adalah $0,250<1,984$ dengan tingkat signifikansi $0,803>0,5 \%$. Ini menunjukkan variabel pelayanan pajak tidak mempengaruhi tingkat kepatuhan wajib pajak orang pribadi.

\subsubsection{Uji Koefisien Detrminasi $\left(\mathbf{R}^{2}\right)$}

Koefisien Determinasi $\left(R^{2}\right)$ pada intinya mengukur seberapa jauh kemampuan model varibel independen dalam menerangkan variasi variabel dependen.

Tabel 14. Hasil Uji Koefisien Determinasi $\left(\mathbf{R}^{2}\right)$

\begin{tabular}{l|r|r|r|r|r|}
\hline Model & R & R Square & $\begin{array}{c}\text { Adjusted R } \\
\text { Square }\end{array}$ & $\begin{array}{r}\text { Std. Error } \\
\text { of the } \\
\text { Estimate }\end{array}$ & $\begin{array}{r}\text { Durbin- } \\
\text { Watson }\end{array}$ \\
\hline 1 &, $546^{\mathrm{a}}$ & 0,298 & 0,277 & 1,355 & 1,892 \\
\hline
\end{tabular}
a. Predictors: (Constant), Pelayanan Pajak, Kesadaran WP, Sanksi
Pajak
b. Dependent Variable: KepatuhanWPOP

Sumber : Data Primer yang diolah, 2019

Pada model terlihat $\mathrm{R} 0,546$ berarti hubungan antar variasi dari kepatuhan wajib pajak orang pribadi sebesar 54,6\% bahwa korelasi (keeratan hubungan) antara tingkat partisipasi dan 3 variabel independen lainnya cukup erat.

1. Hasil uji koefisien determinasi menunjukkan bahwa nilai $\mathrm{R}$ Square sebesar 0,298 (29,8\%) variasi dari Kepatuhan Wajib Pajak Orang Pribadi bisa dijelaskan oleh variasi dari ketiga variabel independennya. Sedangkan sisanya sebesar 70,2\% dijelaskan oleh sebab-sebab lain yang tidak disertakan dalam penelitian ini.

2. Std Error of the estimate merupakan kesalahan standar dari penaksiran bernilai 1,355 .

\section{KESIMPULAN DAN SARAN}

\subsection{Kesimpulan}

1. Tingkat kepatuhan perpajakan yang tinggi dari wajib pajak dapat dicapai dengan cara memberikan sanksi pajak kepada wajib pajak. Berdasarkan Uji Regresi Linear Berganda di peroleh persamaan sebagai berikut:

$\mathrm{Y}=15,072+0,030 \times 1+0,607 \times 2+$ $0,030 \times 3+\mathrm{e}$

Artinya bahwa dalam penelitian ini responden cenderung sudah memiliki kepatuhan pajak tanpa adanya faktorfaktor dalam penelitian ini. Adapun dari 3 variabel independen diatas, 
hanya sanksi pajaklah yang memberikan pengaruh yang signifikan dan meningkatkan kepatuhan wajib pajak. Sementara kesadaran wajib pajak dan pelayanan pajak tidak memberikan pengaruh yang signifikan.

2. Berdasarkan uji $\mathrm{T}$ diketahui bahwa variabel sanksi pajak berpengaruh dan signifikan terhadap tingkat kepatuhan wajib pajak. Artinya ada dua variabel yang tidak mempengaruhi tingkat kepatuhan wajib pajak orang pribadi yaitu variabel kesadaran wajib pajak dan variabel pelayanan pajak.

3. Berdasarkan uji $\mathrm{F}$ diketahui bahwa variabel kesadaran wajib pajak, sanksi pajak dan pelayanan pajak secara simultan dan signifikan terhadap tingkat kepatuhan wajib pajak orang pribadi. Artinya ketiga variabel tersebut secara bersama-sama memberikan pengaruh yang signifikan terhadap Kepatuhan wajib pajak orang pribadi.

4. Dengan $\mathrm{R}^{2}$ sebesar $29,8 \%$, faktorfaktor yang mempengaruhi tingkat kepatuhan wajib pajak orang pribadi $29,8 \%$ berasal dari variabel yang terdapat dalam persamaan regresi. Faktor-faktor lain yang mempengaruhi tingkat kepatuhan wajib pajak orang pribadi diluar dari variabel yang telah diteliti sebesar 70,2\%.

\subsection{SARAN}

Berdasarkan kesimpulan di atas, maka saran-saran yang dapat diberikan terkait Kesadaran wajib pajak, Sanksi pajak dan Pelayanan pajak terhadap Kepatuhan wajib pajak orang pribadi adalah sebagai berikut:

1. Kesadaran wajib pajak perlu ditingkatkan dengan cara mensosialisasikan akan pentingnya membayar pajak. Sosialisasi ini dapat melalui iklan di televisi, radio maupun surat kabar serta media lainnya. Bila perlu sering diadakannya drop box di beberapa tempat keramaian oleh Direktorat Jenderal Pajak (DJP) untuk mempermudah penyerahan SPT Tahunan.

2. Sanksi pajak khususnya sanksi denda harus ditingkatkan untuk disosialisasikan dengan baik kepada para wajib pajak agar wajib pajak dapat memahami hal-hal yang berkaitan dengan pelaksanaan denda serta penyebab-penyebab dikenakannya suatu sanksi denda terhadap wajib pajak.

3. Pelayanan pajak harus terus ditingkatkan untuk membangun kepercayaan wajib pajak dan meningkatkan kepatuhan wajib pajak. Upaya peningkatan kualitas pelayanan dapat dilakukan dengan cara mencakup reformasi dibidang pelayanan yang harus dimulai dari aspek yang paling besar yaitu pola pikir, pola tindak, tata busana serta tutur kata dalam berkomunikasi, selain itu peningkatan kualitas kemampuan teknis pegawai dalam bidang perpajakan.

4. Bagi peneliti lain yang tertarik untuk melakukan kajian di bidang yang sama dapat menggunakan variabel-variabel yang tidak digunakan dalam penelitian ini, sehingga dapat ditemukan variabel baru yang akan meningkatkan mempengaruhi kepatuhan wajib pajak seperti penggunaan $e-S P T$ dan $e$ Filling.

\section{DAFTAR PUSTAKA}

Devano, Sony dan Rahayu, Siti Kurnia. 2006. Perpajakan, Konsep, Teori dan Isu. Kencana Media Group: Jakarta.

Ghozali, Imam. 2001. Aplikasi Analisis Multivariate dengan Program SPSS (Edisi Kedua). Badan Penerbit Universitas Diponegoro: Semarang.

Jatmiko, Agus Nugroho. 2006. Pengaruh Sikap Wajib Pajak pada Pelaksanaan 
Sanksi Denda, Pelayanan Fiskus dan

Kesadaran Perpajakan Terhadap

Kepatuhan Wajib Pajak. Studi Empiris

Terhadap Wajib Pajak Orang Pribadi

di Kota Semarang. Universitas

Diponegoro. Tesis Magister

Akuntansi.

Resmi, Siti. 2009. Perpajakan: Teori dan

Kasus. Edisi Kelima. Salemba Empat:

Yogyakarta.

Rahayu, Siti Kurnia. 2010. Perpajakan

Indonesia: Konsep dan Aspek Formal.

Graha Ilmu: Jakarta.

Riduwan. 2005. Belajar Mudah Penelitian Untuk Guru, Karyawan dan Peneliti

Pemula. Alfabeta: Bandung.

Zain, Mohammad. 2004. Manajemen

Perpajakan. Edisi Kedua. Salemba

Empat: Jakarta. 